\title{
(2) OPEN ACCESS \\ What does informal access to misoprostol in Colombia look like? A mystery client methodology in Bogotá and the Coffee Axis
}

\author{
Ann M Moore (D) ,' Nakeisha Blades, ${ }^{1}$ Juliette Ortiz, ${ }^{2}$ \\ Hannah Whitehead, ${ }^{1}$ Cristina Villarreal $^{2}$
}

- Additional material is published online only. To view please visit the journal online (http://dx.doi.org/10.1136/ bmjsrh-2019-200572).

${ }^{1}$ Division of Research, Guttmacher Institute, New York, New York, USA

${ }^{2}$ Research Area, Fundación Oriéntame, Bogotá, Colombia

\section{Correspondence to}

Dr Ann M Moore, Research, Guttmacher Institute, New York, NY 10038-4723, USA; amoore@ guttmacher.org

The work was previously presented at the 2018 Clacai: Consorcio Latinoamericano contra el aborto inseguro conference in Quito, Ecuador (October, 2018), at the 2019 Population Association of America meetings in Austin (April, 2019) and at the 2019 CLACAl conference in Santa Cruz, Bolivia (June, 2019)

Received 23 December 2019 Revised 18 February 2020 Accepted 26 February 2020 Published Online First 5 July 2020

\section{D) Check for updates}

(c) Author(s) (or their employer(s)) 2020. Re-use permitted under CC BY-NC. No commercial re-use. See rights and permissions. Published by BMJ.

To cite: Moore AM, Blades N, Ortiz J, et al. BMJ Sex Reprod Health 2020;46:294-300.

\section{ABSTRACT}

Introduction In 2006, abortion was

decriminalised in Colombia under certain

circumstances. Yet, women avail themselves

of ways to terminate pregnancy outside of the

formal health system. This study explored how

drug sellers engage with women who attempt to

purchase misoprostol from them.

Methods A mapping exercise was undertaken to list small-chain and independent drug stores in two regions in Colombia. A sample $(n=558)$ of drug stores was selected from this list and visited by mystery clients between November and December 2017. Mystery clients sought to obtain a medication to bring back a delayed period, and described the experience, the information obtained and the medications proffered in exit interviews.

Results Misoprostol was offered for purchase in $15 \%$ of the visits; in half of visits, only information about misoprostol was shared, while no information about misoprostol was provided on the remaining visits. Over half of sellers who refused to sell any medication provided referrals, most commonly to an abortion provider. Among visits which included discussion of misoprostol, two out of five sellers provided dosage instructions with most recommending the minimum adequate dosage. Mystery clients received little information on the physical effects to expect with the use of misoprostol and possible complications.

Conclusions As misoprostol is being obtained from some drug sellers without a prescription, capacitating this cadre with at least a minimum of standardised information on dosage, routes of administration and expected effects and outcomes have the potential to improve reproductive health outcomes for women who choose to terminate pregnancies this way in colombia.
\end{abstract}

\section{Key messages}

Even though abortion became less restricted in Colombia in 2006, informal access to misoprostol is one way that women induce abortion.

- Mystery clients attempting to purchase misoprostol received very little information on how to use the drug correctly or what to expect when taking it.

- Drug sellers require greater training on misoprostol to help improve the quality of information women get; this has the potential to improve abortion safety.

\section{INTRODUCTION}

In 2006, Colombia lifted its absolute ban on induced abortions and legalised the procedure under three circumstances: when the pregnancy threatens the life or mental or physical health of the woman as certified by a doctor, when the fetus has an abnormality incompatible with life, and when the pregnancy results from rape or incest. ${ }^{1}$ Misoprostol was approved for medical abortion by the National Institution of Medication Surveillance (Colombia) in 2007; mifepristone was approved 10 years later. The Ministry of Health $(\mathrm{MOH})$ (Colombia) guidelines for medical abortion recommend the use of misoprostol alone up to 12 weeks of pregnancy, or in combination with mifepristone up to 10 weeks of pregnancy. Both misoprostol and mifepristone are legally available with a prescription; the combi-pack is not available. Misoprostol is possible to access without a prescription while mifepristone is not accessible outside of facilities. 
Since the change in law, women have reported being denied legal abortion, or having multiple obstacles put into their way. ${ }^{2}$ The most recent abortion incidence study in the country (conducted in 2008) found almost all abortions were occurring outside of the legal context, and that half were induced using misoprostol. ${ }^{3}$ This was shortly after misoprostol was approved; since then, misoprostol has likely become increasingly accessible. Without additional evidence to suggest a change in the situation observed in 2008, women's experiences acquiring misoprostol without a prescription to induce abortion demanded further inquiry. We undertook a study on women's access to misoprostol without a prescription from drug sellers to examine:

a. Whether women are offered a chance to buy misoprostol.

b. What information drug sellers give women that try to buy misoprostol.

c. What quantity of misoprostol is sold, and what instructions on use are provided.

Gaining a better understanding of women's experiences when they seek to acquire drugs from drug sellers to terminate a pregnancy outside of the health sector allows new insights into women's pathways to abortion and demand for post-abortion care. Furthermore, it provides information on drug sellers' knowledge about how to administer misoprostol safely and effectively.

\section{METHODS}

The study was a collaboration between the Guttmacher Institute, a sexual and reproductive health research and policy institute in the USA, and Fundación Oriéntame, a service provider and research organisation based in Colombia. Data collection took place in Bogotá and the Coffee Axis between November and December 2017. These two locations have concentrations of reproductive medical services that serve the population of those areas and women in the surrounding vicinity.

\section{Sample}

For over 10 years, Oriéntame has engaged with drug sellers in these areas to provide evidence-based information and training on contraception and legal abortion to increase sellers' knowledge and improve the quality of services provided to women seeking sexual and reproductive health information. They have assembled a list of drug sellers in these regions through this work. Prior to data collection, fieldworkers conducted a mapping exercise beginning with this list, and visiting municipalities in these areas to confirm that listed sites were still functioning, update address information and identify new sites. The listing yielded 1239 small, independent drug stores in Bogotá and 538 in the Coffee Axis. Using this updated list, we purposively sampled all of the stores that had referred to an abortion provider in the past year, and randomly selected a matching sample of drug stores that did not refer clients to an abortion provider $(\mathrm{n}=566)$. Smaller pharmacies were selected because they serve as community resources for many types of basic health information. Additionally, they are are environments in which it's easier to hold a private conversation with the drug seller, some of whom women may already have relationships with. For these reasons, they are the preferred sources of misoprostol acquired informally from drug stores.

\section{Data collection}

We employed eight professional mystery clients and four exit interviewers, all trained on the study protocol and instrument. To prepare mystery clients to pose as women who wanted something to bring back their periods, we provided a profile: 20 years old, unmarried, nulliparous, with 1 year of university education and experiencing a 2-month menstrual delay. We selected that profile because, according to Oriéntame's client demographics, women of that age and education most frequently seek abortions at their facilities, and likely overall. Mystery clients were trained to follow a script, provide specific responses to questions posed to them and probe in specific ways for more information to ensure consistency in the data collected. The script had mystery clients gather as much information as the drug seller was willing to provide about any medication that would bring back her period including how to use the drug, what physical effects she could expect and whether she might experience complications. At each site, mystery clients were allowed to spend up to 50000 Colombian pesos ( $\sim$ US\$17) on any offered medications, and they were allowed to negotiate prices. This amount was based on the costs set by the $\mathrm{MOH}$ for misoprostol.

In line with best practice guidelines, directly following each visit the exit interviewer administered a survey to the mystery client. ${ }^{4-8}$ These structured interviews addressed all aspects of the interaction with the drug seller: whether the client was offered anything to bring back her period, what was offered, whether she received instructions on how to use the drug(s) and what to expect after taking them, how to recognise complications, and whether the recommended drug(s) was/were purchased. Mystery clients were also asked to report whether other people were within earshot during the exchange, the demeanour of the seller and any other observations about the interaction that might be of note. Data were collected on Android tablets using the SurveyCTO data collection platform V.2.40 (Cambridge, MA, USA and Washington, DC).

We sought only one interaction with each drug seller. If mystery clients were unable to make contact with a drug seller after two visits (eg, the pharmacy was not open on either occasion), if the store was not at the listed address, or if the store was a duplicate of another store in the listing, the site was replaced once with another facility located within the same 
study area. Drug stores that had previously referred to an abortion provider were sampled at $100 \%$ and therefore could not be replaced $(n=8) ; 41$ stores were replaced. The Comité de Ética en Investigacion de la Fundación Oriéntame (Colombia) and the Institutional Review Board of the Guttmacher Institute both approved this protocol.

\section{Analysis}

The current WHO guidelines for misoprostol-only regimens advise a minimum of $800 \mathrm{mcg}$ to be taken for pregnancies up to 12 weeks of gestation, with no maximum dosage limit. ${ }^{9}$ We used this to classify whether the amount of misoprostol provided was adequate.

Descriptive analyses of visit outcomes (ie, medications offered, reasons for refusals) and information communicated by sellers (ie, how to administer misoprostol, what physical symptoms to expect) were conducted on all completed exit interviews in Stata V.15.0 (State College, TX).

\section{Patient and public involvement}

There was no patient and public involvement in this study.

\section{RESULTS}

A total of 558 visits were completed, 301 in Bogotá and 257 in the Coffee Axis. Drug sellers were evenly split by sex in Bogotá, while there were more male drug sellers in the Coffee Axis $(58 \%$ men vs $42 \%$ women). According to the mystery clients, the drug sellers they interacted with in both areas appeared to be older than 40 years of age. In almost half (45\%) of the visits, mystery clients described the drug seller's behaviour towards them as negative: hostile, unfriendly or threatening. Another fifth of drug sellers were described as positive (helpful, friendly), while the remaining drug sellers were described as neutral (data not shown).

\section{Buying misoprostol}

In one-third of the interactions, information about misoprostol was not shared during the visit. Drug sellers provided information about misoprostol in half of the visits, and in the remaining $15 \%$ of the visits drug sellers indicated the drug was available for purchase without a prescription. During the visits where any medication was offered for purchase, three out of four drug sellers suggested the mystery client buy misoprostol alone; 11\% were offered misoprostol plus either an injection (usually oxytocin or a progesterone-based injectable); $2 \%$ suggested misoprostol with another drug, such as a contraceptive pill; and $13 \%$ were offered non-abortifacient drugs such as emergency contraceptives (table 1). In both regions, $97 \%$ of sellers quoted a cost above US $\$ 17$, the amount we supplied to the mystery clients for each visit, and
Table 1 Outcome of mystery client visit to drug sellers by region and total, Colombia 2017

\begin{tabular}{|c|c|c|c|c|c|c|}
\hline & \multicolumn{4}{|c|}{ Study area } & & \\
\hline & \multicolumn{2}{|c|}{ Bogotá } & \multicolumn{2}{|c|}{ Coffee Axis } & \multicolumn{2}{|l|}{ Total } \\
\hline & $\%$ & $\mathbf{n}$ & $\%$ & $\mathbf{n}$ & $\%$ & $\mathbf{n}$ \\
\hline & \multicolumn{2}{|c|}{$(n=301)$} & \multicolumn{2}{|c|}{$(n=257)$} & \multicolumn{2}{|c|}{$(n=558)$} \\
\hline \multicolumn{7}{|l|}{ Outcome of visit } \\
\hline $\begin{array}{l}\text { No information on } \\
\text { misoprostol provided }\end{array}$ & 39.2 & 118 & 27.2 & 70 & 33.7 & 188 \\
\hline $\begin{array}{l}\text { Only information on } \\
\text { misoprostol provided }\end{array}$ & 46.2 & 139 & 56.8 & 146 & 51.1 & 285 \\
\hline \multirow[t]{2}{*}{$\begin{array}{l}\text { Misoprostol available } \\
\text { for purchase }\end{array}$} & 14.7 & 44 & 16 & 41 & 15.3 & 85 \\
\hline & \multicolumn{2}{|c|}{$(n=56)$} & \multicolumn{2}{|c|}{$(n=42)$} & \multicolumn{2}{|c|}{$(n=98)$} \\
\hline \multicolumn{7}{|c|}{ Medications client had opportunity to purchase* } \\
\hline Misoprostol only & 66.1 & 37 & 83.3 & 35 & 73.5 & 72 \\
\hline Misoprostol+injection & 10.7 & 6 & 11.9 & 5 & 11.2 & 11 \\
\hline $\begin{array}{l}\text { Misoprostol+other } \\
\text { drugs }\end{array}$ & 1.8 & 1 & 2.4 & 1 & 2 & 2 \\
\hline \multirow{2}{*}{$\begin{array}{l}\text { Non-abortifacient } \\
\text { drugs }\end{array}$} & 21.4 & 12 & 2.4 & 1 & 13.3 & 13 \\
\hline & \multicolumn{2}{|c|}{$(n=245)$} & \multicolumn{2}{|c|}{$(n=215)$} & \multicolumn{2}{|c|}{$(n=460)$} \\
\hline \multicolumn{7}{|l|}{ Reasons for refusalt } \\
\hline $\begin{array}{l}\text { Does not sell drugs to } \\
\text { induce abortion }\end{array}$ & 68.2 & 167 & 81.4 & 175 & 74.3 & 342 \\
\hline $\begin{array}{l}\text { Medicine is only to } \\
\text { be used in a health } \\
\text { facility }\end{array}$ & 18.4 & 45 & 20.5 & 44 & 19.3 & 89 \\
\hline $\begin{array}{l}\text { Does not know what } \\
\text { to sell for this purpose }\end{array}$ & 9.4 & 23 & 7 & 15 & 8.3 & 38 \\
\hline $\begin{array}{l}\text { Woman needs a } \\
\text { prescription }\end{array}$ & 6.9 & 17 & 10.7 & 23 & 8.7 & 40 \\
\hline $\begin{array}{l}\text { Disagrees with } \\
\text { abortion }\end{array}$ & 11 & 27 & 16.3 & 35 & 13.5 & 62 \\
\hline $\begin{array}{l}\text { Pregnancy too far } \\
\text { along to terminate }\end{array}$ & 6.1 & 15 & 4.2 & 9 & 5.2 & 24 \\
\hline $\begin{array}{l}\text { No drug in stock to } \\
\text { induce an abortion }\end{array}$ & 2.9 & 7 & 1.9 & 4 & 2.4 & 11 \\
\hline $\begin{array}{l}\text { Wants to avoid } \\
\text { problems associated } \\
\text { with selling } \\
\text { misoprostol }\end{array}$ & 2.4 & 6 & 3.3 & 7 & 2.8 & 13 \\
\hline Client is young & 1.6 & 4 & 1.4 & 3 & 1.5 & 7 \\
\hline $\begin{array}{l}\text { Seller did not give } \\
\text { reason }\end{array}$ & 6.5 & 16 & 3.3 & 7 & 5 & 23 \\
\hline
\end{tabular}

Seller gave client a referral

\begin{tabular}{lllllll} 
Yes & 52.7 & 129 & 61.9 & 133 & 57 & 262 \\
No & 47.3 & 116 & 38.1 & 82 & 43 & 198 \\
\hline & $\mathbf{( n = 1 2 9 )}$ & $(\mathbf{n}=\mathbf{1 3 3})$ & $(\mathbf{n}=\mathbf{2 6 2})$ \\
\hline $\begin{array}{l}\text { Types of referrals given } \neq \\
\begin{array}{l}\text { Health centre or } \\
\text { health professional }\end{array}\end{array}$ & 82.2 & 106 & 70.7 & 94 & 76.3 & 200 \\
\hline \begin{tabular}{l} 
Other pharmacy \\
\hline
\end{tabular} & 11.6 & 15 & 26.3 & 35 & 19.1 & 50 \\
\hline & & & & & & Continued
\end{tabular}


Table 1 Continued

\begin{tabular}{|c|c|c|c|c|c|c|}
\hline & \multicolumn{2}{|c|}{$(n=129)$} & \multicolumn{2}{|c|}{$(n=133)$} & \multicolumn{2}{|c|}{$(n=262)$} \\
\hline $\begin{array}{l}\text { Advised to go to a } \\
\text { seller in another city }\end{array}$ & 9.3 & 12 & 7.5 & 10 & 8.4 & 22 \\
\hline $\begin{array}{l}\text { Curandero/traditional } \\
\text { healer }\end{array}$ & 0 & 0 & 1.5 & - & 0.8 & 2 \\
\hline \multicolumn{7}{|c|}{$\begin{array}{l}\text { *Injections include oxytocin, progesterone-based injectables and contraceptive } \\
\text { injectables. Other pills and drugs include oral contraceptives, emergency } \\
\text { contraception, antibiotics and other drugs not named by the seller. Unspecified } \\
\text { pills were not identified by name, but were often described in a manner that } \\
\text { suggests the seller was referring to misoprostol. } \\
\text { tSellers may have been refusing to sell misoprostol or any medication to bring } \\
\text { back a period/cause an abortion. } \\
\ddagger \text { As respondents could select more than one option, column percentages do } \\
\text { not add up to } 100 \% \text {. }\end{array}$} \\
\hline
\end{tabular}

so the drugs were only purchased in eight visits (data not shown).

Most of the drug sellers who refused to sell anything to the mystery client stated that they did not sell drugs to induce abortion. One in five sellers told the mystery client that the medicine could only be used in a health facility, and fewer than one in 10 reported that the mystery client needed a prescription or that $\mathrm{s} /$ he does not know what to sell for this purpose (table 1). Over half of drug sellers who refused to sell any medication referred the mystery client elsewhere. The most common referral location was to a health centre; in $85 \%$ of Bogotá visits and $72 \%$ of Coffee Axis visits the health centre to which the mystery client was referred was a place which provided abortions (data not shown).

\section{Instructions on use of misoprostol and what to expect}

Following the $\mathrm{WHO}$ guidelines on misoprostol use for terminating pregnancies up to 12 completed weeks gestation, ${ }^{9}$ we classified dosage instructions as either below the recommended dosage $(<800 \mu \mathrm{g})$, or meeting the minimum recommended dosage (at least $800 \mu \mathrm{g})$. Among visits which included mention of misoprostol $(n=370)$, three in five sellers did not provide any dosage instructions (table 2). Among the remaining sellers who did share this information $(\mathrm{n}=158)$, nearly all $(92 \%)$ advised taking a dosage that met the minimum recommendation.

Most commonly, sellers advised a single dose of either four (46\%) or six pills (21\%, not shown), each one $200 \mu \mathrm{g}$.

Drug sellers' recommendations on the route of administration were not always accompanied by dosage information. According to WHO guidelines, the optimal routes of administration for misoprostol are sublingual, buccal and vaginal insertion. ${ }^{9}$ Only nine drug sellers advised mystery clients to use these routes. Two in five drug sellers suggested that mystery clients insert some pills vaginally and swallow the rest. Over half did not provide any administration information.

In the interactions in which misoprostol was discussed, most mystery clients received very little information on the physical effects and possible complications. We captured whether information was offered spontaneously, after being prompted by the mystery client or not at all. The physical effect mentioned most often by sellers was to expect bleeding for a few days, but only one in 10 women were told this information spontaneously. An additional 35\% were told this when the drug seller was prompted (figure 1). Fewer than one in 10 drug sellers spontaneously advised women to expect cramps and pain; almost none were told to expect diarrhoea, fevers or chills. In only $5 \%$ of cases did drug sellers tell women spontaneously that some symptoms might indicate the need for medical follow-up; an additional 7\% indicated this when prompted.

Table 2 Information from drug sellers on use of misoprostol and what to expect by region and total, Colombia 2017

\begin{tabular}{|c|c|c|c|c|c|c|}
\hline & \multicolumn{4}{|c|}{ Study area } & \multirow{2}{*}{\multicolumn{2}{|c|}{ Total }} \\
\hline & \multicolumn{2}{|l|}{ Bogotá } & \multicolumn{2}{|c|}{ Coffee Axis } & & \\
\hline & $\%$ & $\mathbf{n}$ & $\%$ & $\mathbf{n}$ & $\%$ & $\mathbf{n}$ \\
\hline & \multicolumn{2}{|l|}{$(n=183)$} & \multicolumn{2}{|l|}{$(n=187)$} & \multicolumn{2}{|l|}{$(n=370)$} \\
\hline \multicolumn{7}{|l|}{ Accuracy of dosage instructions* } \\
\hline Below recommended dose $(<800 \mu \mathrm{g})$ & 4.4 & 8 & 2.1 & 4 & 3.2 & 12 \\
\hline At least minimum recommended dose $(\geq 800 \mu \mathrm{g})$ & 39.3 & 72 & 39.6 & 74 & 39.5 & 146 \\
\hline No dosage instructions provided & 56.3 & 103 & 58.3 & 109 & 57.3 & 212 \\
\hline \multicolumn{7}{|l|}{ Accuracy of administration route instructions* } \\
\hline Advised optimal routes & 2.7 & 5 & 2.1 & 4 & 2.4 & 9 \\
\hline Advised mixture of optimal and suboptimal routes & 36.1 & 66 & 36.9 & 69 & 36.5 & 135 \\
\hline Advised suboptimal routes & 3.3 & 6 & 3.7 & 7 & 3.5 & -3 \\
\hline No administration instructions provided & 57.9 & 106 & 57.2 & 107 & 57.6 & 213 \\
\hline
\end{tabular}




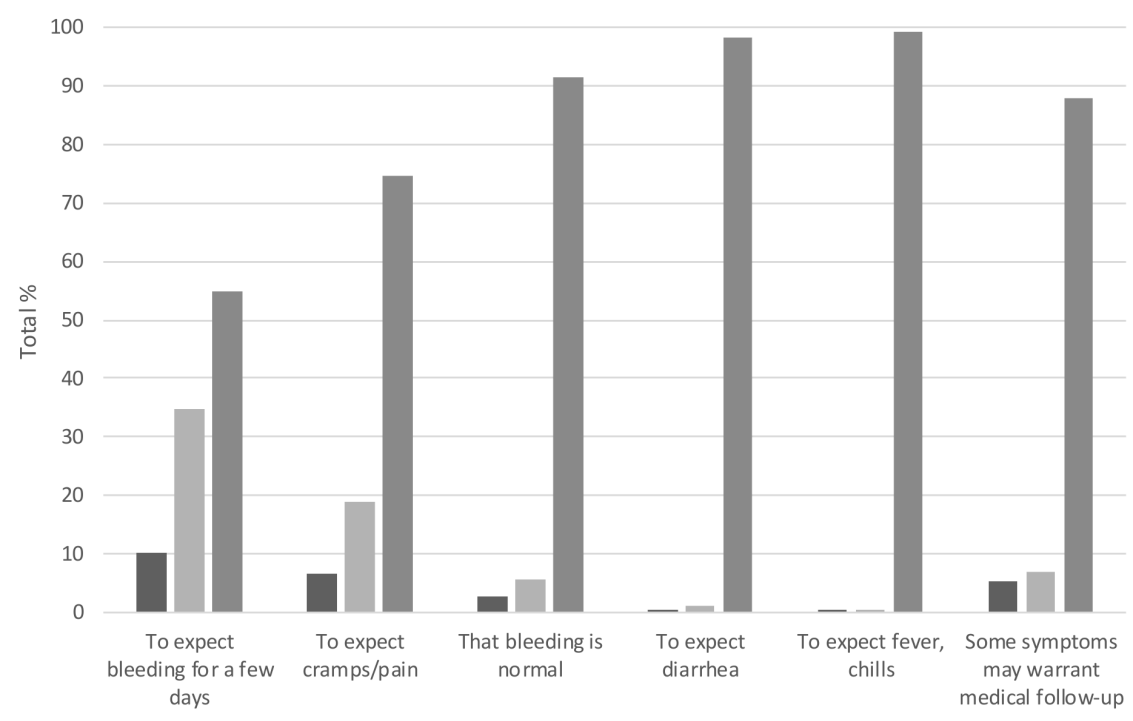

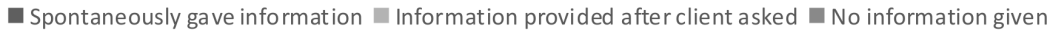

Figure 1 Physical effects and complications of misoprostol on which sellers advised, Colombia 2017.

\section{DISCUSSION}

This is the first study using mystery clients to attempt to buy misoprostol conducted in Colombia. No highquality studies have been published using mystery client methods in Latin America to acquire misoprostol for over a decade. ${ }^{10}$ Our mystery clients show that when women in Colombia seek misoprostol outside of health facility channels, while most will not be able to buy misoprostol, they are likely to be able to get some information about it. The finding that $57 \%$ of drug sellers provided referrals, $76 \%$ of which were to a health centre or a health professional, can be interpreted as a responsible strategy to connect to women to legal abortion care from trained professionals. As abortion in Colombia is only legal under specific circumstances, only a portion of these women will meet these requirements. For women who do not meet the requirements, or who opt not to approach a formal healthcare provider, these referrals may be akin to being turned away. Some of these women will likely seek misoprostol elsewhere, some will continue their pregnancies while others will try to abort in more dangerous ways.

Sellers in our study that offered a drug for purchase sometimes offered more medications than necessary (misoprostol +injections) or ineffective ones (emergency contraception). The information they provided on how to use misoprostol varied in quality and scope, and at times contradicted recommended practice, potentially leaving clients underequipped to manage the outcomes and possible complications associated with its use.
The knowledge gaps displayed by sellers demonstrate a need to educate drug sellers on correct misoprostol administration. It falls within the purview of the national $\mathrm{MOH}$ to provide education for pharmacists on abortion legality, appropriate dosages of drugs needed to conduct medical abortions and the formalisation of referrals.Previous studies have found an improvement in drug sellers' knowledge about misoprostol administration through targeted interventions such as infographic tools. ${ }^{11} 12$ Another study in Nepal examined drug sellers' ability to dispense medical abortion successfully within a harm reduction framework. ${ }^{13}$ Sellers trained under this approach not only were able to dispense medicalabortion safely but the women also reported no serious complications during their abortion process. However, a recent study in Bangladesh highlights challenges to these efforts: sellers may lack financial incentives to provide comprehensive counselling, even with additional training they may be uncertain about their knowledge, and clients may be uncomfortable discussing this topic with drug sellers. ${ }^{11}$ In addition, scaling up effective interventions may be cost prohibitive. ${ }^{11}$ Improving drug sellers' knowledge about both misoprostol and mifepristone, with the expectation that mifepristone may become increasingly accessible in Colombia, holds the potential to improve the information women receive about how to safely terminate an unwanted pregnancy in Colombia. More knowledgeable drug sellers and women might also reduce the administration of unnecessary injections or the sale and purchase of ineffective drugs in place of misoprostol and mifepristone; this may also reduce potential complications and delayed abortions. 
Future research is needed on the efficacy of the misoprostol and mifepristone, when and if it becomes available, purchased through informal channels in Colombia. In addition, it would be important to identify which injection(s) women are being sold in combination with misoprostol to assess the safety and effects of this. It would also be valuable to conduct mystery client interactions and/or interviews with other vendors who sell misoprostol: street vendors and online sellers.

\section{Limitations}

Our study only included brick and mortar drug sellers; this is not the only source of misoprostol in Colombia. In addition, drug sellers charged more for misoprostol than anticipated and so we were only able to buy the drugs in a small number of interactions. We only presented one profile of a mystery client; it is possible that another profile may have resulted in more offers of misoprostol among this sample. Lastly, misoprostol availability may vary greatly month-to-month. If this study had been conducted a few months earlier or a few months later, the results may have been quite different.

\section{CONCLUSION}

Access to misoprostol is a harm-reduction strategy that has the potential to protect women's reproductive health when they desire to terminate unwanted pregnancies in locations where abortion is restricted. More and more healthcare is becoming user-controlled; misoprostol is one of the best examples of new technologies that make it possible to move reproductive healthcare into the hands of the user. This option is of particular importance in restrictive policy environments including Colombia. WHO identifies that there are uncertainties about pharmacists' ability to access eligibility for medical abortion, administrate the medications and manage the process and side-effects independently, and assess completion of the procedure and the need for further clinic-based follow-up, ${ }^{14}$ and that further research is needed to address these uncertainties. These results demonstrate the distance yet to go in Colombia to have a cadre of well-capacitated drug sellers safely providing medical abortion.

\section{Twitter Ann M Moore@Marie77Ann}

Acknowledgements The authors would like to thank the members of the advisory committee for their input on the study design, feedback on preliminary results, and guidance on the framing and dissemination of the study findings. The authors would also like to acknowledge Akinrinola Bankole of the Guttmacher Institute for his contributions to the study design and review of the manuscript, and Sophia Sadinsky and Adesegun Fatusi (both of the Guttmacher Institute), Elena Prada (formerly Guttmacher Institute) and María Mercedes Vivas (Oriéntame) for their input on an earlier draft. This study benefitted from input from a larger three-country study team, including staff from Guttmacher Institute, Academy for Health Development (AHEAD, Nigeria), Centre for Research, Evaluation Resources and Development (CRERD, Nigeria), Oriéntame (Colombia) and Reconstra (Indonesia). Finally, the authors would like to express their appreciation to all the study participants.

Collaborators Additional contributions from individuals who are not authors: Elena Prada contributed to the design of the study, trained and supervised fieldworkers, contributed to the interpretation of the data, and reviewed an earlier version of the manuscript. Akinrinola Bankole contributed to the study design, contributed to the exit interview survey, contributed to the interpretation of the data; and reviewed an earlier version of the manuscript. Adesegun Fatusi, María Mercedes Vivas and Sophia Sadinsky also reviewed an earlier draft of this paper. The advisory committee reviewed and commented on the study design, provided feedback on preliminary results, and gave guidance on the framing and dissemination of the study findings. Rachel Murro managed the formatting and submission of the manuscript to the journal.

Contributors AMM: Conceived of the study; created the study design, conceptualised aspects of the analysis and drafted the majority of the manuscript; also managed the majority of the revisions to the manuscript based on reviewer feedback. NB: Designed the exit interview survey; trained fieldworkers on the mystery client component; drew the sample; led on the analysis of the mystery client data; contributed to the writing of the manuscript; and managed a substantial number of revisions to the manuscript based on reviewer feedback. JO: Contributed to the design of the exit interview survey; trained and supervised fieldworkers on the mystery client component; identified the universe; contributed to the interpretation of the data; reviewed the manuscript and provided comments; answered numerous questions asked by reviewers which contributed to the revision of the manuscript. HW: Contributed to the design of the exit interview survey; implemented changes to the exit interview survey; participated in data analysis; reviewed the manuscript and provided comments. CV: Contributed to the study design; participated in the fieldwork training and supervision; participated in the identification of the universe; contributed to the interpretation of the data; reviewed the manuscript and provided comments; answered numerous questions asked by reviewers which contributed to the revision of the manuscript.

Funding The study on which this article is based was made possible by UK Aid from the UK Government (project \#203177-101), the Dutch Ministry of Foreign Affairs (activity \#4000000282) and an anonymous foundation.

Disclaimer The views expressed are those of the authors and do not necessarily reflect the positions and policies of the donors. The funder of the study had no role in study design, data collection, data analysis, data interpretation, or writing of the report. All authors had full access to the data, and the corresponding author had final responsibility for the decision to submit for publication.

Competing interests None declared.

Patient and public involvement Patients and/or the public were not involved in the design, or conduct, or reporting, or dissemination plans of this research.

Patient consent for publication Not required.

Provenance and peer review Not commissioned; externally peer reviewed.

Data availability statement Data are available upon reasonable request. We are ready to collaborate with others who may be interested in using these data; a member of the study team must be part of the analysis team and the confidentiality of our respondents will be protected at all times.

Open access This is an open access article distributed in accordance with the Creative Commons Attribution Non Commercial (CC BY-NC 4.0) license, which permits others to distribute, remix, adapt, build upon this work noncommercially, and license their derivative works on different terms, provided the original work is properly cited, appropriate 
credit is given, any changes made indicated, and the use is noncommercial. See: http://creativecommons.org/licenses/by-nc/4. $0 /$.

\section{ORCID iD}

Ann M Moore http://orcid.org/0000-0002-6914-1974

\section{REFERENCES}

1 Center for Reproductive Rights. The world's abortion laws, 2020. Available: https://reproductiverights.org/ worldabortionlaws? country= COL [Accessed September 1, 2019].

2 Stifani BM, Gil Urbano L, Gonzalez Velez AC, et al. Abortion as a human right: the struggle to implement the abortion law in Colombia. Int J Gynaecol Obstet 2018;143(Suppl 4):12-18.

3 Prada E, Biddlecom A, Singh S. Induced abortion in Colombia: new estimates and change between 1989 and 2008. Int Perspect Sex Reprod Health 2011;37:114-24.

4 Boyce C, Neale P. Using mystery clients: a guide to using mystery clients for evaluation input. Watertown, MA: Pathfinder International, 2006. https://pdfs.semanticscholar. org/0f1e/79fa0e2c77ca9e27148fc8ae3324276ddbe0.pdf

5 Huda FA, Ngo TD, Ahmed A, et al. Availability and provision of misoprostol and other medicines for menstrual regulation among pharmacies in Bangladesh via mystery client survey. Int J Gynaecol Obstet 2014;124:164-8.

6 Lara D, Abuabara K, Grossman D, et al. Pharmacy provision of medical abortifacients in a Latin American City. Contraception 2006;74:394-9.
7 Madden JM, Quick JD, Ross-Degnan D, et al. Undercover careseekers: simulated clients in the study of health provider behavior in developing countries. Soc Sci Med 1997;45:146582.

8 Mchome Z, Richards E, Nnko S, et al. A 'mystery client' evaluation of adolescent sexual and reproductive health services in health facilities from two regions in Tanzania. PLoS One 2015; 10:e120822.

9 World Health Organization. Medical management of abortion. Geneva: WHO, 2018. https://www.who.int/reproductivehealth/ publications/medical-management-abortion/en/

10 Footman K, Keenan K, Reiss K, et al. Medical abortion provision by pharmacies and drug sellers in low- and middleincome countries: a systematic review. Stud Fam Plann 2018;49:57-70.

11 Reiss K, Keenan K, Church K, et al. Drug Seller provision practices and knowledge of misoprostol in Bangladesh. Int Perspect Sex Reprod Health 2019;45:45-54.

12 Diamond-Smith N, Phillips B, Percher J, et al. An intervention to improve the quality of medication abortion knowledge among pharmacists in India. Int J Gynecol Obstet 2019;147:356-62.

13 Tamang A, Puri M, Masud S, et al. Medical abortion can be provided safely and effectively by pharmacy workers trained within a harm reduction framework: Nepal. Contraception 2018;97:137-43.

14 World Health Organization, ed. Health worker roles in providing safe abortion care and post-abortion contraception. Geneva: WHO, 2015. https://www.who.int/reproductivehealth/ publications/unsafe_abortion/abortion-task-shifting/en/ 